\title{
Functional Outcome of Distal Radius Fracture Treated by Closed Reduction and K Wiring in Elderly Population
}

\author{
Aravind Shanbhag ${ }^{1}$, Ramdas Shenoy B. ${ }^{2}$, Visakh Pandikasalayil ${ }^{3}$, Aditya H. Kumar ${ }^{4}$, Praveen J. ${ }^{5}$ \\ 1, 2, 3, 4, 5 Department of Orthopaedics, K.S. Hegde Medical Academy, Mangalore, Karnataka, India.
}

\section{ABSTRACT}

\section{BACKGROUND}

Fracture distal end of radius is very common in the elderly population. ${ }^{1}$ Pre-existing osteoporosis causes fracture due to fall from standing height or low energy injuries. Most of the studies in distal radius fracture has been on the radiological outcome and have included all age group. These fractures differ in the elderly in terms of low energy involved to cause the fracture as well as the quality of the bone being osteoporotic.

\section{METHODS}

This is a retrospective descriptive study conducted among 74 patients of distal radius fracture managed by closed reduction and $\mathrm{k}$ wiring. PRWE questionnaire at the end of one year from the time of surgery was used to collect the data.

\section{RESULTS}

Out of the 74 cases, 61 (67.5\%) had excellent outcome with PRWE score of 1 - 10 at the end of one year. 10 patients (18\%) had good outcome with PRWE score of 11 20, and 3 patients had PRWE score of 21 - 40 (13\%) which was an average outcome.

\section{CONCLUSIONS}

Distal radial fractures managed by percutaneous $\mathrm{k}$ wires have a good functional outcome in the elderly patients.

\section{KEY WORDS}

Distal Radius, Elderly, Osteoporosis, Functional Outcome
Corresponding Author: Dr. Aravind Shanbhag, Orthopaedic Surgeon, Nitte Gajria, Speciality Hospital, Tellar Road, Karkala, Mangalore, (DK), Karnataka,

E-mail: aravindshanbhag@gmail.com

DOI: $10.14260 / \mathrm{jemds} / 2020 / 803$

How to Cite This Article: Shanbhag A, Shenoy RB, Pandikasalayil V, et al. Functional outcome of distal radius fracture treated by closed reduction and $k$ wiring in elderly population. J Evolution Med Dent Sci 2020;9(48):3660-3664, DOI: 10.14260/jemds/2020/803

Submission 11-08-2020,

Peer Review 07-10-2020,

Acceptance 13-10-2020,

Published 30-11-2020.

Copyright (C) 2020 JEMDS. This is an open access article distributed under Creative Commons Attribution License [Attribution 4.0 International (CC BY 4.0)] 


\section{BACKGROUND}

Fracture distal end radius is very common in the elderly population. ${ }^{1}$ Pre-existing osteoporosis causes the fracture due to fall from standing height or low energy injuries. Most of these fractures are dorsally displaced and comminuted. There have been various modalities of treatment ranging from closed reduction and cast immobilization, percutaneous K-wire fixation, fixation with volar or dorsal plates (locking or nonlocking), bridge plating, use of an external fixator, or a combination of these techniques. ${ }^{2}$ The newer option with plates have an incremental cost on health care. ${ }^{3}$ In the present scenario of health care in India cost-effective management becomes a priority with most of the population covered by government sponsored health scheme ${ }^{4,5}$ Closed reduction and casting though most economical, will result in a collapse of fracture inside the cast and loss of reduction, mainly in the elderly population with pre-existing osteoporosis with dorsal cortex comminution. ${ }^{6,7}$ Most of the studies in distal radius fracture have been on the radiological outcome and have included all age group. These fractures differ in the elderly in terms of low energy involved to cause the fracture as well as the quality of the bone being osteoporotic. In the present study we study the functional outcome of distal radius fracture in the elderly patients at one year, treated with percutaneous $\mathrm{K}$ wiring by using Patient Rated Wrist Evaluation (PRWE) rather than the radiological outcome.

\section{METHODS}

This study was a retrospective descriptive study, conducted at a secondary hospital at Karkala, a town in coastal South India and it was carried out by accessing case record files from December 2016 to February 2019, of patients at the Department of Orthopaedics at the secondary hospital.

Aim of this study was to determine the incidence of fracture distal radius in elderly patients and their distribution with respect to different age groups. Also, to determine if fracture severity varies with different age groups as per OTA (Orthopaedic Trauma Association) classification. To find out the long term (minimum of 12 months) functional outcome in these cases when managed by closed reduction and $\mathrm{K}$ wire fixation. And also, to see if the functional outcome is dependent on the fracture type (OTA), or age. To also see the economic viability of the above said procedure and morbidity associated with this procedure.

All adult patients who had sustained closed distal radius fractures as diagnosed by x-ray were included in the study. Patients who were above the age of 55 years and had sustained a trivial trauma / fall from standing height causing fracture of distal radius were included in the study. Patients who had other associated injuries that could have hampered their rehabilitation post-surgery and patients who had neurological illness and so could not answer the questionnaire were excluded from the study.

A total of 90 patient files were identified and were contacted on the phone and requested for participating in the study. 10 patients refused to participate, and 6 were excluded as they were deceased at the time of the survey. So a total of 74 patients were included in the study.

Analysis of the patient files showed the following details about them. All the patients were managed by closed reduction and $\mathrm{K}$ wire fixation of the distal radius under the axillary block. Closed reduction was done with traction and counter traction and confirmed under C-arm. Fractures were held with $1.8 \mathrm{~mm}$ or $1.5 \mathrm{~mm} \mathrm{k}$ wires. 3 - $5 \mathrm{k}$ wires were used for fixing the fracture based on the amount of comminution. K-wires were introduced from the distal to the proximal end. For a few cases (OTA type C), Kapandji technique was used, where the K-wire was inserted into the fracture site to be used as a buttress to prevent collapse. Postoperatively, they were immobilized with dorsal and volar slab. The average duration of surgery was 32 mins (range $20-42$ mins). Average stay in the hospital was 2 days (range 1 - 4 days.). Check x rays were done at 1 week, 2 weeks, and finger, elbow and shoulder mobilization was encouraged after surgery. Patients were also treated with calcium and vitamin D supplements after surgery. Slab and Kwires were removed at 6 weeks after surgery and the wrist and forearm were mobilized. Patients were then seen weekly for the next 4 weeks for supervising the rehabilitation.

Patients who were willing to participate were asked to answer the Performa containing their details and PRWE questionnaire. It was made sure that there was a minimum time period of twelve months since injury in all cases when they filled the questionnaire (average 16 months, range 13 18 months.) and the scores were tabulated.

PRWE is a 15-item patient-reported questionnaire. It has two subscales. 1. Pain score subscale determining pain which consists of 5 questions (with response ranging from $0=$ no pain $-10=$ worst ever pain).

1. Pain at rest.

2. When doing a task with repeated movements.

3. When lifting a heavy object.

4. When it is at its worst.

5. How often do u have pain?

Function score - Subscale to determine function which consists of 10 items. This is further subdivided into two parts. First part with six questions pertaining to the specific activities with response ranging from $0=$ no difficulty to $10=$ unable to do.

1. Turn a knob using my affected hand.

2. Cut meat or a vegetable / fruit with knife using affected hand.

3. Fasten the buttons on the shirt.

4. Use the affected hand to push up from the chair.

5. Use the hand to lift a $5 \mathrm{Kg}(10 \mathrm{lb})$ object.

6. Use bathroom tissue or use the affected hand to clean the perineum.

Second part with 4 items about usual activities with the response range same as above.

1. Personal care activities. (Dressing and washing)

2. Household work like cleaning and maintenance.

3. Usual everyday work.

4. Recreational activities. 
The function score is determined by the sum of $2 \mathrm{a}$ and $2 \mathrm{~b}$ divided by 2 the total score = pain score (out of 50) + function score (out of 50). The scores of individual items rating pain and disability from $0-10$ were provided qualitative descriptors defined as follows: none (0) minimal $(1-2)$, mild $(3-4)$, moderate $(5-6)$, severe $(7-8)$ or very severe $(9-10)$. For the pain scale item on the frequency of pain, the descriptors used were; never $(0)$, rarely $(1-2)$, occasionally $(3-4)$, frequent $(5-6)$, very frequently $(7-8)$ or constant $(9$ - 10) pain.

Descriptive data analysis was done using SPSS 19.0 software and the results were analysed.

\begin{tabular}{|c|c|c|c|c|c|}
\hline \multicolumn{6}{|c|}{ RESULTS } \\
\hline Descriptor & Item & Pain & $\begin{array}{l}\text { Specific } \\
\text { Activity }\end{array}$ & $\begin{array}{c}\text { Usual } \\
\text { Activity }\end{array}$ & Total \\
\hline None & 0 & 0 & 0 & 0 & 0 \\
\hline Minimal & 1- 2 & $1-10$ & $0-12$ & $0-8$ & $1-20$ \\
\hline Mild & $3-4$ & $11-20$ & $13-24$ & $9-16$ & $21-40$ \\
\hline Moderate & $5-6$ & $21-30$ & $25-36$ & $17-24$ & $41-60$ \\
\hline Severe & $7-8$ & $31-40$ & $37-48$ & $25-32$ & $61-80$ \\
\hline Very Severe & $9-10$ & $41-50$ & $48-60$ & $32-40$ & $81-100$ \\
\hline
\end{tabular}

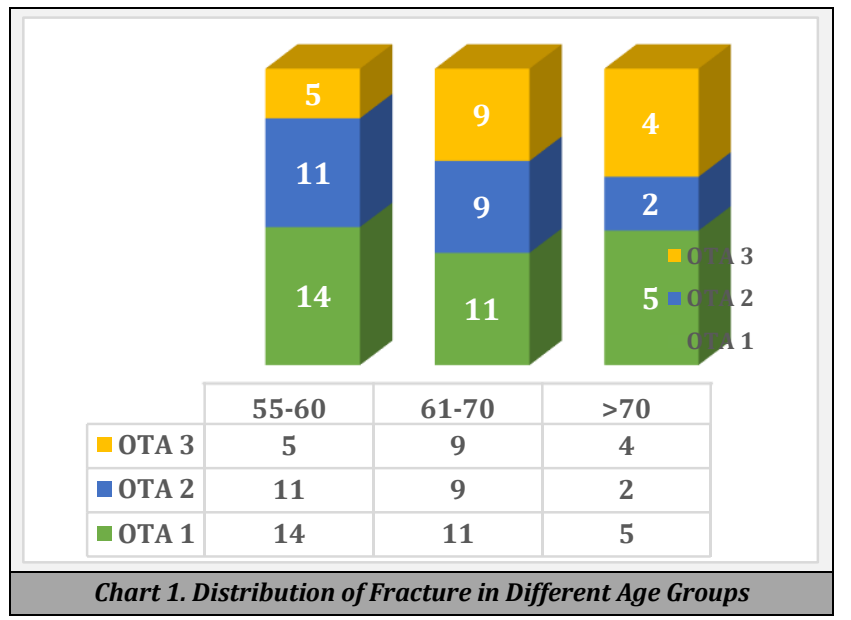

\begin{tabular}{|cc|}
\hline Age & $\mathbf{6 4}$ (55 - 95) \\
Dight $67(90 \%)$ & Left $07(10 \%)$ \\
Sex & Male 24 (32.43\%) female $50(67.57 \%)$ \\
Injured Hand & Right $40(54 \%)$ \\
& Left $34(46 \%)$ \\
Dominant Hand Injured & Yes $64 \%$ \\
Type of Fracture -Extra Articular & No $36 \%$ \\
- Partial Articular & $30(40.5 \%)$ \\
- Intra Articular & $21(28.38 \%)$ \\
Medical problems None & $23(31.08 \%)$ \\
Hypertension & 10 \\
DM & 35 \\
Arthritis & 47 \\
Others & 15 \\
Low & 18 \\
Moderate & 10 \\
High & 34 \\
Occupational Demand of the hand & 30 \\
Baseline work Status & \\
Working & 30 \\
Retired & 17 \\
Homemaker & 16 \\
Self-care only & 6 \\
Bedridden due to other Problems & 5 \\
\hline Table Characteristics of 74 Patients of Distal Radius Fracture \\
\hline
\end{tabular}

There was a positive co relation between the type of fracture and PRWE score ( $\mathrm{p}$ value < 0.05; effect size 0.243). There was no co-relation between age and the PRWE outcome when analysed with Pearson correlation (sig 2 tailed - 0.436) There was also no correlation between age and the fracture type when analysed with Pearson correlation (sig 2 tailed 0.440 ).
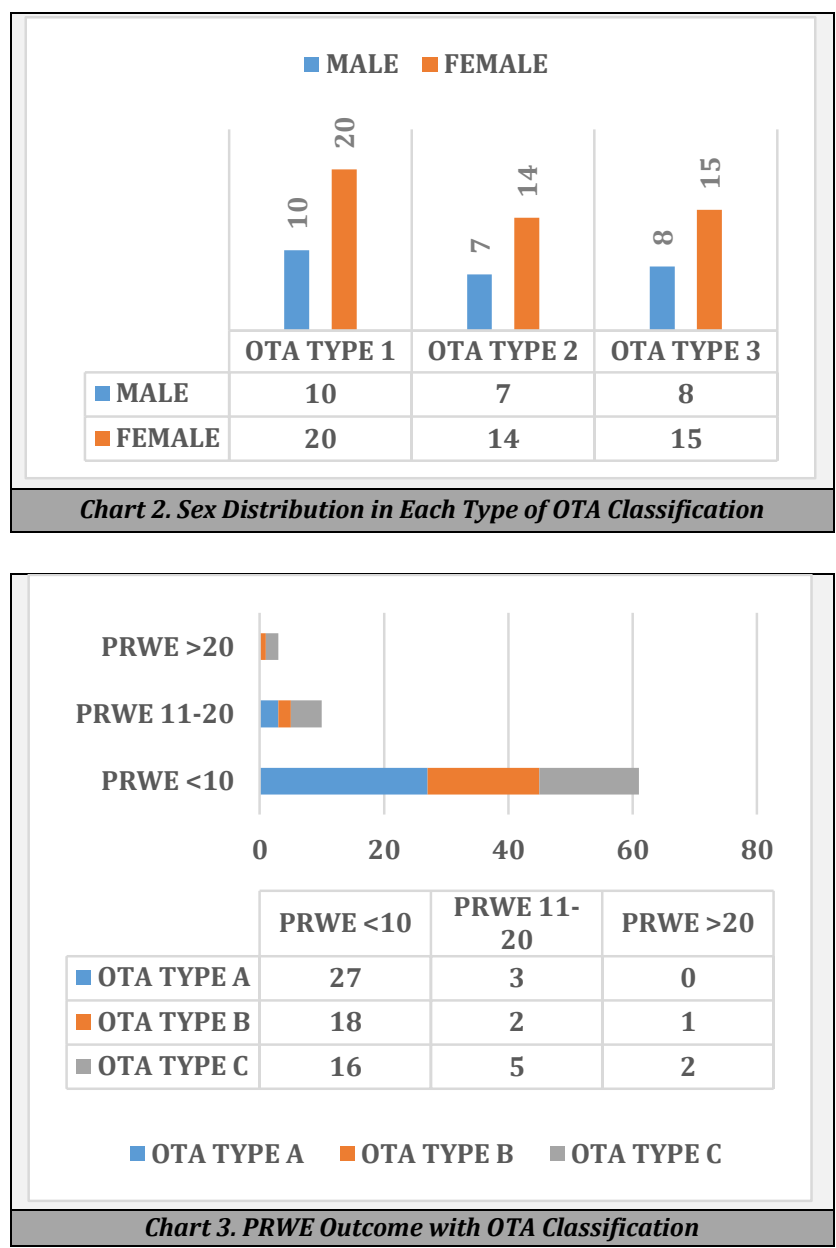

15 cases $(20 \%)$ had pin tract infection of the site which settled completely after the removal of wires at 6 weeks. 5 cases had frozen shoulder and were treated by physiotherapy for the same, and they had completely recovered by 3 months. Out of the 74 cases $61(67.5 \%$ ) had excellent outcome with PRWE score of $1-10$ at the end of one year. 10 patients $(18 \%)$ had good outcome with PRWE score of $11-20$, and 3 patients had PRWE score of 21 - 40 (13\%) which was an average outcome. The functional outcome seen in this trial is consistent with that seen in other studies of recovery following fracture of the distal radius. Mac Dermid et al. ${ }^{8}$ conducted a prospective cohort study of 129 patients with a fracture of the distal radius. They reported a mean PRWE questionnaire score of 13.5 (SD 17.0) at 12 months. This is consistent with our reported values. Out of the 61 with excellent outcome (PRWE score of 1 - 10) 27 cases were OTA type A, 18 OTA type B and 16 were OTA TYPE C. Out of the 10 with a good outcome (PRWE score of 11 - 20) 3 cases were OTA type A, 2 OTA type B and 5 were OTA TYPE C. Out of the 3 cases which had average outcome (PRWE score of $21-40$ ), 1 was OTA type b and 2 were OTA type c.

Fracture severity does not change with increase in age as all fractures are found in all three ages. Functional outcome 
has no correlation with age but does have positive co-relation with type of fracture (OTA). There was a positive correlation between the type of fracture and PRWE score ( $p$ value $<0.05$; Effect size: 0.241). There was no co-relation between age and the PRWE outcome when analysed with Pearson correlation (sig 2 tailed - 0.436). There was also no correlation between age and the fracture type when analysed with Pearson correlation. (sig 2 tailed - 0.440). The average cost incurred for the treatment / surgery was 6000 and the average stay was 2 days.

\section{DISCUSSION}

Distal radius fracture is bimodal in distribution, with the first peak being in the young individuals with high energy injury and high expectation in terms of outcome and second peak being in elderly with low energy injury, osteoporotic bone and low expectations in terms of outcome. ${ }^{9}$ At the turn of the century newer innovations have made fixation of comminuted osteoporotic fractures possible with plates. ${ }^{10}$ Volar plating though allows early motion of the wrist and has better radiological outcome, has a high complication rate and cost issues.11,12 Since the introduction of plates the incidence of surgeries has gone up. ${ }^{13}$ Though there are publications showing advantage of plating over $\mathrm{K}$ wiring the magnitude of the difference is not clinically significant. ${ }^{2}$ We have used PRWE to assess the functional outcome as it's a better tool to assess the outcome as compared to the other tools. ${ }^{14,15}$ PRWE is a patient-reported outcome which is very important in assessing patient status post-intervention. ${ }^{15} \mathrm{~A}$ well-developed patient-related outcome measure (PROM) can help in making health care decisions by evaluating a patient perspective. PRWE is a patient reported outcome measure which intends to quantify pain and disability arising from the wrist conditions. ${ }^{16}$

In our functional outcome study 64 cases had excellent to good outcomes at the end of one year with PRWE score of less than 20. Since the average age of patients in the study is 66 (range 52 - 95) the outcome is significant in terms of management of distal radius fractures in the elderly. Also the fact that most of them were low energy injury points to the fact that they had pre-existing osteoporosis. Our results are also comparable to the literature in terms of outcome following wrist injuries in terms of PRWE. 8,9

As per the recently published UK-DRAFFT (Distal Radius Acute Fracture Fixation Trial) (multi-centric randomized control trial) there is no difference in functional outcome of dorsally displaced distal radius fractures treated with $\mathrm{K}$ wiring or volar plating at the end of one year. ${ }^{9}$ They randomly assigned 350 cases of distal radius fracture in 18 centres in to two groups of treatment, one where plating was done and another where $\mathrm{K}$ wiring was done. They did not find a statistically significant differences in outcome in terms of PRWE scores at any point time. The economic analysis suggested 20 times higher cost in the group treated by plates as compared to that with $\mathrm{K}$ wires. This DRAFFT study concluded that the plating had no benefit over the $\mathrm{K}$ wire method.

\section{CONCLUSIONS}

Distal radius fracture is a frequently seen injury in the elderly population. ${ }^{1}$ Treatment has been controversial with various options. In a developing country like India, where affordable health care is a priority, cost-effectiveness is an important criterion. ${ }^{4}$ Though multiple studies have been done in the past which suggest otherwise, none of them evaluated the long term outcome. ${ }^{9}$ The above study concludes that distal radial fractures managed by percutaneous $\mathrm{k}$ wires have a good functional outcome in the elderly patients. However, more studies are needed with regard to different $\mathrm{k}$ wire techniques used for different types of distal radius fractures.

Data sharing statement provided by the authors is available with the full text of this article at jemds.com.

Financial or other competing interests: None.

Disclosure forms provided by the authors are available with the full text of this article at jemds.com.

\section{REFERENCES}

[1] Navarro CM, Brolund A, Ekholm C, et al. Treatment of radius or ulna fractures in the elderly: a systematic review covering effectiveness, safety, economic aspects and current practice. PLoS One 2019;14(3):e0214362.

[2] Chaudhry H, Kleinlugtenbelt YV, Mundi R, et al. Are volar locking plates superior to percutaneous k-wires for distal radius fractures? A meta-analysis. Clin Orthop Relat Res 2015;473(9):3017-27.

[3] Shauver MJ, Yin H, Banerjee M, et al. Current and future national costs to medicare for the treatment of distal radius fracture in the elderly. J Hand Surg 2011;36(8):1282-7.

[4] Chatterjee S, Levin C, Laxminarayan R. Unit cost of medical services at different hospitals in India. PLoS One 2013;8(7):e69728.

[5] Kusuma YS, Pal M, Babu BV. Health insurance: awareness, utilization, and its determinants among the urban poor in Delhi, India. J Epidemiol Glob Health 2018;8(1-2):69-76.

[6] Zengin EC, Ozcan C, Aslan C, et al. Cast immobilization versus volar locking plate fixation of AO type $\mathrm{C}$ distal radial fractures in patients aged 60 years and older. Acta Orthop Traumatol Turc 2019;53(1):15-8.

[7] Weil WM, Trumble TE. Treatment of distal radius fractures with intrafocal (kapandji) pinning and supplemental skeletal stabilization. Hand Clin 2005;21(3):317-28.

[8] MacDermid JC, Roth JH, Richards RS. Pain and disability reported in the year following a distal radius fracture: a cohort study. BMC Musculoskelet Disord 2003;4(1):24.

[9] Costa ML, Achten J, Parsons NR, et al. UK DRAFFT - a randomised controlled trial of percutaneous fixation with kirschner wires versus volar locking-plate fixation in the treatment of adult patients with a dorsally displaced fracture of the distal radius. BMC Musculoskelet Disord 2011;12(1):201.

[10] Saving J, Ponzer S, Enocson A, et al. Distal radius fractures-regional variation in treatment regimens. PLoS One 2018;13(11):e0207702. 
[11] Navarro CM, Pettersson HJ, Enocson A. Complications after distal radius fracture surgery: results from a Swedish Nationwide Registry Study. J Orthop Trauma 2015;9(2):e36-e42.

[12] Arora R, Lutz M, Hennerbichler A, et al. Complications following internal fixation of unstable distal radius fracture with a palmar locking-plate. J Orthop Trauma 2007;21(5):316-22.

[13] Wilcke MKT, Hammerberg H, Adolphson PY. Epidemiology and changed surgical treatment methods for fractures of the distal radius: a registry analysis of 42,583 patients in Stockholm County, Sweden, 20042010. Acta Orthop 2013;84(3):292-6.
[14] Goldhahn J, Beaton D, Ladd A, et al. Recommendation for measuring clinical outcome in distal radius fractures: a core set of domains for standardized reporting in clinical practice and research. Arch Orthop Trauma Surg 2014;134(2):197-205.

[15] MacDermid JC. Patient-reported outcomes: state-of-theart hand surgery and future applications. Hand Clin 2014;30(3):293-304.

[16] MacDermid JC. Development of a scale for patient rating of wrist pain and disability. J Hand Ther 1996;9(2):17883. 